

\section{Sumário}

I. CRônicas

A Favor de uma Corte Latino-Americana de Justiça ..................................................... 3 Nitish Monebhurrun

Sobre A SOluÇão JUdicial de CONTROvérsias Na AMÉRICA LATINA 7 Lucas Carlos Lima

A Favor de uma Corte Latino-Americana de Justiça - Uma Reação sobre a Legalidade e A Legitimidade De Seu Desenho Institucional............................................................15

Arthur Roberto Capella Giannattasio

O Estudo do Direito Internacional sob uma Nova Perspectiva: Nossa Experiência na Philip C. Jessup International Moot Court Competition............................................20 Ana Vitória Muniz Bokos, Igor Medeiros Maia, Jefferson Seidy Sonobe Hable, Gabriel de Oliveira Borba, Gilda Nogueira Paes Cambraia e Nayara Lima Rocha Da Cruz

Revisión de laudos de arbitrajes de inversión 2019: I Encuentro Anual (Santiago de

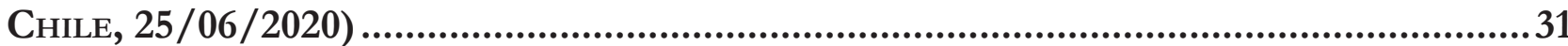
Andrés Delgado Casteleiro e Ivette Esis

II. Dossiê: Populismo e Direito Internacional / Populism and Internatio-

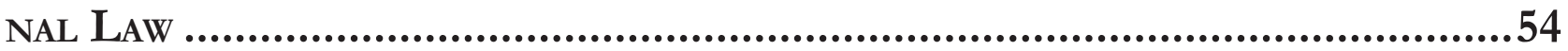

Editorial: Populism and International Law: Global South Perspectives .56 Lucas Lixinski e Fabio Morosini

Editorial: Populismo e Direito Internacional: Perspectivas do Sul Global .61 Lucas Lixinski e Fabio Morosini 
Between Science and populism: the Brazilian Response to COVID-19 from the Perspective of the legal determinants of Global Health

Deisy de Freitas Lima Ventura e Jameson Martins

Populism, ENVIronmental LAW, AND THE POST-PANDEMiC ORDER Alessandra Lehmen

Populism and the Evangelical church in Latin America: how anti-LGBTI forces TRIED TO STOP THE COLOMBIAN PEACE AGREEMENT Julia Assmann de Freitas Macedo e Fabrízio Conte Jacobucci

“Deus EM Davos": o Direito INTERnACIONAL ENTRE REACIONÁRIOS E NEOLIBERAIS NO GOVERNO BOLSONARO 121

Lucas Tasquetto e João Roriz

CHINESE POPULISM IN THE 1920s, EXTRATERRITORIALITY AND INTERNATIONAL LAW 139 Wanshu Cong

CONCEPTUALIZING UNILATERALISM, FRAGMENTATIONISM AND STATISM IN A POPULISM CONTEXT: A RISE OF POPULIST INTERNATIONAL LAW? 162 Wei Shen e Carrie Shu Shang

AUTONOMÍA ADMINISTRATIVA SIN AUTONOMÍA POLÍTICA: LA APLICACIÓN DEL MODELO "UN PAÍS dos SISTEMAs" eN HoNg Kong 186 Juan Enrique Serrano Moreno

III. Artigos sobre outros temas...................................................... 197

Um TWAiler entre nós? As contribuições de Celso Duvivier de Albuquerque Mello PARA O DIREITO INTERNACIONAL (CRÍTICO) NO BRASIL .................................................... 199

Fabio Morosini e Matheus Leichtweis

DEMOCRACIES IN DANGER: ARE JUDICIAL DIALOGUES MEANS TO REFRAIN SETBACKS IN LATIN America?.

Melina Girardi Fachin e Bruna Nowak 


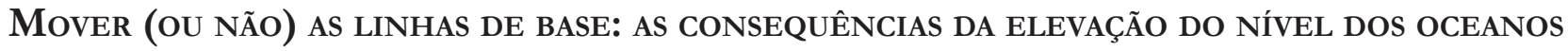
SOBRE AS ZONAS MARÍTIMAS DOS PEQUENOS ESTADOS INSULARES EM DESENVOLVIMENTO E AS ALTERNATIVAS JURÍDICAS PARA REDUZIR SEUS IMPACTOS

Alexandre Pereira da Silva

A mineração em águas profundas no Pacífico 263 Pierre-Jean Bordahandy

Dual Nationality and International Law in times of Globalization. Challenges and Opportunities for Consular Assistance and Diplomatic Protection in RECENT CASES. 288

Walter Arevalo-Ramirez e Robert Joseph Blaise Maclean

Expulsion of aliens: the application of International Law by Chilean Superior Courts 309

Regina Ingrid Díaz Tolosa

O TIPO PENAL BRASILEIRO DE PROMOÇÃo DE MIGRAÇÃO ILEGAL E O PRINCÍPIO DA NÃO CRIMINALIZAÇÃo DA MOBILIDADE HUMANA

Regina Cândido Lima e Silva Santos e Deilton Ribeiro Brasil

INDICADORES TRANSNACIONAIS DE CORRUPÇÃO AMBIENTAL: A OPACIDADE NA TRANSPARÊNCIA INTERNACIONAL

Márcio Ricardo Staffen

SubTRAÇÃo INTERNACIONAL DE CRIANÇAS: ANÁLISE DAS EXCEÇÕES AO RETORNO IMEDIATO DO MENOR À RESIDÊNCIA HABITUAL E CRÍTICA AO ENQUADRAMENTO DA VIOLÊNCIA DOMÉSTICA COMO FLEXIBILIDADE PERMISSIVA

Vivian Daniele Rocha Gabriel

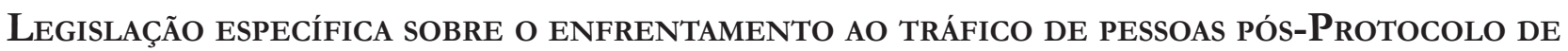
Palermo (2000): análise do Estado de Moçambique 383

Mercia Cardoso de Souza, Guirino Dinis José Nhatave e Francisco Horácio da Silva Frota 
IV. Artigos traduzidos

DIREITO INTERNACIONAL DO RECONHECIMENTO

Emmanuelle Tourme-Jouannet e Tradutor: Ademar Pozzatti Junior

V. RESENHAS

Fabio Costa Morosini, Gabriel Lee Mac Fadden Santos, Valentina Fonseca da Luz e Vinicius Tejadas Maia 


\title{
O Estudo do Direito Internacional sob uma Nova Perspectiva: Nossa Experiência na Philip C. Jessup International Moot Court Competition
}

\author{
Ana Vitória Muniz Bokos \\ Igor Medeiros Maia \\ Jefferson Seidy Sonobe Hable \\ Gabriel de Oliveira Borba \\ Gilda Nogueira Paes Cambraia \\ Nayara Lima Rocha Da Cruz *
}

Como estudantes de Direito no Brasil temos algumas expectativas básicas, nos é esperado passar no exame de ordem, ter boas notas, comparecer às aulas e cumprir os requisitos curriculares da grade do curso. Esse modelo acaba, muitas vezes, afastando os(as) alunos(as) de experiências extracurriculares e diferentes metodologias de estudo e aprendizado, de modo que a formação jurídica pode ficar prejudicada nesse aspecto.

A aprendizagem do direito na prática, nesse contexto, fica limitada ao estágio obrigatório promovido pelo núcleo de prática jurídica da universidade, destinado aos alunos a partir do sétimo semestre do curso, e às atividades de pesquisa ficam destinadas para os programas de iniciação científica, ou seja, desvinculadas da grade curricular, ou diretamente na escrita do trabalho de conclusão de curso.

A busca por uma experiência diferenciada durante a graduação, portanto, acaba ultrapassando o ambiente da sala de aula e, ainda, se tornando um privilégio daqueles(as) alunos(as) que são, por algum motivo, atraídos para tall $^{1}$. Essa busca, no nosso caso, foi bem sucedida pela nossa experiência no Philip C. Jessup International Law Moot Court Competition.

A prática de tribunais simulados, comumente conhecidos como Moot Courts, é uma metodologia de ensino jurídico que já é amplamente difundida em diversos países de tradição Common Law ${ }^{2}$. Trata-se de um exercício trazido pela simulação de uma sessão de uma corte frente a um caso fictício e complexo, onde as equipes atuam como requerente e requerido. Os juízes, por sua vez, são juristas experientes na área, que atuam como banca julgadora nas etapas de arguição oral. Vale ressaltar que a competição conta com uma etapa escrita, na qual as equipes elaboram documentos jurídicos, os memoriais, de defesa e de acusação, que refletem a vasta e complexa pesquisa jurídica realizada com base no caso em questão.

É evidente que atividades como essa desenvolvem um apurado senso

* Os alunos fazem ou fizeram parte da equipe que representou o Centro Universitário de Brasília na Competição de Tribunal Simulado Jessup
MONEBHURRUN, Nitish et al. O Problema na Formação do(a) Jurista Enquanto Pesquisador(a): Uma Crítica aos Cursos de Direito. 1a. ed. Rio de Janeiro: Processo, 2019. 152 p. v. 1. ISBN 978-85-93741-50-0.

2 AMARAL JÚNIOR, Alberto do et al. O modelo de ensino participativo no Direito Internacional: relato de uma experiência. Revista Direito GV, São Paulo, v. 12, n. 3, p. 632-647, 2016. 
de argumentação jurídica, pesquisa aprofundada, oratória e trabalho em equipe. Ademais, refletem com muito mais propriedade a realidade da prática do Direito e, especialmente, do Direito Internacional, uma vez que trabalham em cima de um caso complexo, mais alinhado às necessidades de um jurista que atua no mundo moderno e globalizado ${ }^{3}$.

A Jessup simula a Corte Internacional de Justiça e inaugurou a prática de Moot Courts nos cursos de Direito, em 1960, na Universidade de Harvard. Iniciou-se como uma competição amistosa entre as equipes da própria Universidade e hoje conta com mais de 700 equipes de universidades diferentes de mais 100 países e jurisdições. Hoje, é a maior e mais prestigiada competição de tribunal simulado do mundo ${ }^{4}$.

Neste sentido, essa imersão no mundo dos Moot courts permitiu que os alunos da graduação do UniCEUB tivessem vivências que estão além dos cursos regulares oferecidos, e que proporcionaram o desenvolvimento de competências e habilidades que em geral, só são adquiridas com a entrada no mercado de trabalho.

Assim, a aplicação prática do Direito, através de sustentações orais em língua estrangeira, no caso o inglês, a exposição a bancas de juízes extremamente qualificados, o planejamento estratégico de argumentos jurídicos e o contato com novas visões metodológicas, transformaram a vida acadêmica dos estudantes de forma única e singular.

A prática de tribunais simulados veio para nós por diferentes canais e motivos, mas com um viés comum: trazer experiências práticas, desenvolver a capacidade de pesquisa, aprimorar a oratória e proporcionar um diferencial curricular durante nossa graduação em Direito.

Assim, nossa experiência, apesar de coletiva, pode ser individualizada com a vivência de cada um, a partir de diferentes aspectos que marcaram nossa passagem na Jessup, seja pela vivência de um Direito prático (1), pela superação da timidez (2), o retorno necessário (3), pela criação de um planejamento estratégico na vida acadêmica (4), pela aparição como um acaso bem su-

BIANCHINI, Carolina Bonini; HAERTEL, Letícia Machado. As competições de julgamento simulado como instrumento de ensino jurídico. Revista da Faculdade de Direito, Universidade de São Paulo, v. 113, p. 737-759, 2018.

4 Mais informações sobre a competição podem ser encontradas no site oficial da Philip C. Jessup International Law Moot Court Competition. Disponível em: https://www.ilsa.org/ . cedido (5) ou trazendo um novo olhar acadêmico (6). Essas experiências, cumuladas, representam o impacto que a participação em Moot Courts pode ter na vida acadêmica, profissional e pessoal dos alunos, demonstrando o resultado da experiência prática (7).

\section{A vivência de um Direito prático 5}

No meu caso, a busca pela pesquisa e pela aplicação prática do Direito, além do que já me era proposta em sala de aula, era uma necessidade que sentia desde o começo do curso. Além disso, o interesse pelo Direito Internacional também me acompanha mesmo antes da matéria aparecer na minha grade do semestre.

O método de aprendizagem do Direito como estava sendo transmitido, com a exceção de alguns poucos professores, me parecia nada atraente e um tanto incompleto se comparado com a complexidade das relações interpessoais e internacionais contemporâneas. Nesse contexto, entendia que seria preciso buscar nas atividades extracurriculares o complemento que me fazia falta na minha vida acadêmica.

A Jessup apareceu na minha universidade em meados de 2017, durante meu sexto semestre de Direito. O Administrador Nacional da Jessup no Brasil iria fazer uma visita a universidade para apresentar a competição para os alunos e lembro de ler o convite com entusiasmo. Após essa apresentação inicial, me inscrevi para o processo seletivo com a certeza que essa experiência era justamente o que eu procurava para preencher a sensação de que estudar Direito era mais do que me parecia.

O pequeno número de alunos(as) participando do processo seletivo foi o primeiro indício de um fato que confirmei claramente mais tarde: a participação em Moot Courts é uma cultura ainda não estabelecida na universidade. É válido salientar que a competição é realizada inteiramente em inglês, o que também é um fator limitante para o estabelecimento dessa cultura. De todo modo, formou-se o primeiro time da minha universidade para a Competição Jessup, composto, na época, por 4 alunos do curso de Direito e um professor orientador, denominado, no universo dos Moot Courts, como coach.

Essa primeira experiência de preparação para a com-

Gilda Nogueira Paes Cambraia. Membro da equipe nas edições de 2018, 2019 e coach na edição 2020. 
petição foi, certamente, o trabalho mais difícil, complexo, sacrificante e engrandecedor que eu havia vivenciado em toda a minha vida acadêmica. A completa pesquisa para a construção dos memoriais e a capacidade de argumentação jurídica para as arguições orais que nos são demandadas durante a preparação da competição a torna uma verdadeira escola de formação de juristas.

Tamanha demanda e dedicação deixou evidente, também, a importância do trabalho em equipe e da liderança, qualidades que são colocadas a prova durante a preparação para a competição. As longas jornadas de pesquisa durantes as férias e feriados, o primeiro contato com o verdadeiro método de argumentação jurídica a ser aplicado e até o abandono de um dos membros do time uma semana antes da entrega dos memoriais foram os aspectos que marcaram esse primeiro contato com a Jessup.

Findada a etapa escrita, começa-se a intensa e desafiadora preparação para a etapa oral, momento que devemos sustentar, diante da Corte Internacional de Justiça simulada, os nossos argumentos jurídicos, fruto de toda a nossa pesquisa, bem como responder a todos os questionamentos concernentes ao caso e ao Direito feitos pelos juízes. É nesse momento que, de fato, temos contato com todos os times do Brasil que passaram pela mesma preparação e competem pela oportunidade de representar o país nas etapas internacionais, em Washington D.C, nos Estados Unidos.

Nas etapas orais do meu primeiro Jessup foi quando percebi a grandiosidade dessa comunidade engajada com o Direito Internacional e com as Moot Courts e como essa prática já é uma cultura em algumas universidades do país. Ficou evidente, ainda, que as equipes mais bem sucedidas são justamente aquelas que possuem uma cultura de Moot Court consolidada.

Após a primeira experiência, com um time de 3 pessoas apenas (as equipes são normalmente compostas por 5 participantes), atuando como oradora de ambas as partes, crescendo e aprendendo um fato novo a cada round e interagindo com tantas pessoas que, com muito compromisso e dedicação, viviam a mesma experiência, tive certeza que nenhuma outra atividade acadêmica poderia me proporcionar crescimento tão rico e completo quanto essa.

Essa primeira experiência fomentou um desejo de ampliar e divulgar os Moot Courts como meio de aprender e ensinar o Direito, juntando pesquisa, argumenta- ção e prática. Nesse momento, confirmei a constatação que fiz no primeiro processo seletivo: a cultura de Moot Courts não era estabelecida, mas agora teria a chance de ser criada. A busca pela construção de uma cultura tribunal simulado na minha universidade é algo que, desde então, tentamos estabelecer e já obtivemos grande avanço, apesar de todas as resistências, obstáculos e frustrações, certos de que é um processo contínuo e em construção.

O crescimento da equipe e avanço na competição nos anos seguintes certamente é um reflexo não só da experiência adquirida, mas de todos os esforços para a consolidação do Moot Court como método de aprendizagem do Direito.

No ano seguinte que participamos já contávamos com uma equipe completa e obtivemos grande avanço, como dois prêmios individuais de $10^{\circ}$ e $2^{\circ}$ melhor orador, para mim e minha dupla de arguição, respectivamente.

Já no fim da graduação continuei engajada, agora como coach, orientando a equipe junto com o professor orientador que nos acompanha desde a primeira edição. Neste ano, viver a Jessup quase que nos bastidores foi um desafio e ao mesmo tempo uma grande satisfação. A equipe não só ganhou o prêmio individual de $1^{\circ}$ melhor orador, como também foi selecionada para participar dos Rounds Internacionais, na qualidade de exbibition team.

O impacto que a participação na Jessup causou e continua causando na minha vida acadêmica e profissional é muito significativo, sendo, certamente, a melhor, mais desafiadora e engrandecedora experiência da minha graduação.

A Competição não só desenvolveu qualidades essenciais em qualquer profissional do direito, como a argumentação jurídica, a capacidade de pesquisa, a oratória e um senso de liderança e trabalho em equipe, mas abriu portas, oportunidades e me apresentou amizades que levarei comigo além da universidade.

A minha experiência com a Jessup confirmou, por fim, que o estudo do Direito deve, de fato, refletir a complexidade do universo em que ele está inserido, e as Moot Courts fazem isso com maestria. 


\section{A superação da timidez ${ }^{6}$}

Em setembro de 2017, foi veiculada no portal da faculdade uma oportunidade de participar da maior competição de direito internacional do mundo. Assim, ao comparecer à reunião, junto a um pequeno e seleto número de alunos(as) participando do processo seletivo, e conhecer do que se tratava, não imaginava que toda a metodologia de ensino que havia aprendido até então, estava prestes a mudar. Uma competição de simulação da Corte Internacional de Justiça, a Philip C. Jessup Moot Court Competition, na qual mais de cem países discutem e estudam o mesmo caso, em uma mesma língua - mal podia esperar para embarcar nesse desafio.

Inicialmente, éramos um grupo de 4 estudantes da graduação, mas no meio do caminho, um abandonou o percurso. De qualquer forma, éramos três estudantes, com olhos brilhando por um debate sobre Direito Internacional, com os especialistas e profissionais mais bem qualificados do mundo.

Recebemos o caso, e de início, tínhamos que apresentar ao nosso professor orientador (coach), os nossos argumentos tanto para o Estado Requerente, como para o Estado Requerido. Sem saber direito como funcionava a pesquisa direcionada à competição, e no âmbito do Direito Internacional, coletei as mais diversas informações, e como boa estudante universitária brasileira, muitas doutrinas.

$\mathrm{Na}$ reunião seguinte, ao perceber que a pesquisa realizada não serviria muito como argumento para aquela defesa, e após uma brilhante exposição do professor que nos orientava acerca de metodologia de pesquisa e como construir uma argumentação, comecei a compreender de que forma uma pesquisa acadêmica deveria ser realizada. Assim, saí da reunião ansiosa para chegar em casa, mergulhar nas fontes do Direito Internacional Público, e construir uma linha de argumentação minimamente defensável, através da aplicação do método que nos foi apresentado.

Aproximadamente trinta rascunhos de sumários depois, começamos a escrever os memoriais, com toda a linha de argumentação que seria defendida oralmente, e que deve ser submetido à organização da competição para avaliação, visto que tal documento compõe a pontuação da equipe.

\footnotetext{
${ }^{6}$ Nayara Lima. Membro da equipe nas edições 2018, 2019 e 2020.
}

Neste sentido, durante o processo de escrita, faltando exatamente três dias para a entrega oficial, um dos membros da equipe não mais apareceu, e então, nós três que restamos, nos juntamos para escrever nesse curto prazo, o que deveria ter sido feito em três meses. Sem dúvidas, esse acontecimento foi o que me trouxe maior aprendizado. A partir daquele momento, aprendi o que era trabalho em equipe, dedicação, foco e amizade.

Digo com plena certeza que, podíamos não ser a equipe mais bem preparada, visto que em tal competição, experiência é um diferencial. Mas, sem hesitação, afirmo que éramos a equipe mais unida, e isso nos rendeu um ótimo desempenho no nosso primeiro ano de competição. Superar nossos medos e dificuldades ao lado de pessoas que te motivam a dar o seu melhor, é sem dúvidas, uma das mais preciosas lições que levarei para a vida.

No ano seguinte, 2018, encantados pela experiência que havíamos tido e almejando que o máximo de colegas também a tivessem, sob a orientação do Prof. Nitish, foi montado um grupo de estudo de tribunal simulado, no qual toda semana devíamos fazer uma sustentação oral sobre um tema por ele sugerido. Tal grupo nos rendeu, para o ano seguinte, uma equipe de 6 pessoas (uma a mais do que oficialmente permitido para compor o time), e um rendimento que passou da $12^{\mathrm{a}}$ para a $7^{\mathrm{a}}$ posição.

Assim, em 2019, realizamos uma simulação para que os estudantes do UniCEUB pudessem conhecer e entender a dinâmica da competição, e ao fim desta, diversos colegas nos procuraram para obter informação de como participar. Na seleção daquele ano, lembro-me que a sala da coordenação do mestrado não foi suficiente para comportar todos os candidatos.

$\mathrm{Na}$ competição, novamente melhoramos o nosso desempenho, além de termos sido convidados a representar o Brasil nas rodadas internacionais em Washington, D.C., o que apesar de não ter ocorrido, em razão da pandemia, demonstra o reconhecimento da equipe na maior competição de Direito Internacional do Mundo.

Agora, em 2020, apesar de todas as circunstâncias excepcionais que estamos enfrentando com a COVID-19, o processo seletivo reuniu 16 pessoas interessadas em representar o UniCEUB na competição.

Como uma das primeiras pessoas a compor a equipe, contribuir e observar o crescimento da implantação 
da cultura de moot courts na faculdade, é algo de que tenho muito orgulho. Há muito, a academia de Direito deixou de ser restrita às matérias ofertadas, e os futuros profissionais precisam se reinventar e adquirir habilidades que serão o seu diferencial mais à frente.

A Jessup me fez desenvolver a competência de pesquisar de forma objetiva, organizar a linha de argumentação de uma maneira lógica, a lidar com pessoas dos mais diferentes tipos, superar um dos meus maiores desafios, que é a timidez, além de me tornar uma pessoa apta a assumir qualquer compromisso, pois aprendi que tenho capacidade técnica para tal.

Antes, pensar em falar em público já era motivo para perder noites de sono. Agora, após todos os treinamentos, técnicas e motivação, estar diante de um púlpito, argumentando e recebendo os mais diversos questionamentos, é algo que me estimula e dá um novo sentido à minha vida acadêmica.

Assim, digo que todo estudante de graduação deveria ter a oportunidade de passar por essa experiência transformadora, pois existe uma graduação antes da competição, e outra após, e só sabe o que é a Jessup, quem viveu a Jessup.

Ver ao longo desses anos diversos estudantes desenvolver uma paixão pela competição assim como eu, me faz ter a certeza de que é uma experiência que muda vidas, e abre um mundo de oportunidades de trabalho, mestrado, cursos de extensão e especializações.

Apesar dos tribunais simulados fazerem parte de uma cultura que ainda vem crescendo a passos de formiga no Brasil, tenho certeza que contribuir para a implantação desta na faculdade em que estudo, deixará um legado que, além de ressignificar a graduação de muitos estudantes, transformará muitas vidas com superações pessoais, assim como foi com a minha.

\section{0 retorno necessário ${ }^{7}$}

A primeira vez que participei da Jessup foi no ano de 2017/2018. A equipe da minha universidade estava se formando, e ainda sem saber ao certo do que se tratava tudo aquilo, eu decidi tentar entrar na equipe. O primei-

Igor Maia. Membro da equipe nas edições 2018 e 2020. Melhor orador da edição 2020. ro contato real que tive com a competição foi através de vídeos que encontrei no YouTube, onde pude assistir às rodadas orais da etapa internacional da competição.

Ainda imerso naquele misto de empolgação e ansiedade, as pesquisas e os treinos se iniciaram. Foi então que percebi qual seria o real valor de toda aquela empreitada. A partir daquele momento constatei que aquela seria a experiência necessária à minha graduação, pelo engrandecimento acadêmico que iria me trazer, seja quanto a pesquisa, seja quanto a escrita ou quanto a oratória.

Por outro lado, a verdade era que desde que eu entrei no curso de direito, tive como objeto claro seguir para advocacia privada, o fato de poder litigar, apresentando e debatendo pontos de vistas claramente opostos me fascinava desde antes da minha entrada no curso de direito. A Jessup, por sua vez, se apresentou como uma primeira oportunidade de adentrar esse mundo. A competição, que havia entrado minha vida de forma repentina, foi a primeira experiência real na advocacia privada que realmente tive. O complexo caso apresentado aos competidores trouxe em suas mais diversas faces as necessidades que todo advogado enfrenta em seu dia-a-dia.

Para melhor elucidar, cabe apenas observar que a competição tem o claro interesse de colocar frente a frente duas ideias opostas, onde cada uma das partes deve defender seu lado, a despeito, inclusive, das crenças pessoais de cada um dos participantes. Além disso, as razões apresentadas por cada um, além de terem um limite de palavras, tem um objetivo claro, se prestando a defender um dos lados. Por fim, os competidores se apresentam perante juízes muito bem qualificados, conhecedores do caso, e que buscam a todo momento testar os conhecimentos de cada um dos competidores. Ou seja, em uma só oportunidade nós poderíamos exercitar a pesquisa direcionada, pautando-se necessariamente em fontes sólidas e consolidadas no meio jurídico internacional, desenvolver uma lógica jurídica plausível e apresentar as razões perante juízes oralmente, com o dever claro de convencê-los que o nosso ponto era o correto, sanando todas as eventuais dúvidas. Por fim, devíamos fazer tudo isso em inglês, sendo, para tanto, necessário o conhecimento da linguagem técnica legal na língua anglo-saxônica.

Foi então a primeira vez em que me senti exercendo, mesmo que de forma simulada, a profissão que eu 
busco em meu futuro. Após muita preparação, horas de pesquisa, superação de fatos inesperados (a saída de um dos integrantes do grupo), nós seguíamos para a nossa primeira participação na rodada nacional da competição. Me deparei então com uma realidade totalmente diferente daquela que estava me preparando para enfrentar. Me lembro bem que em minha primeira rodada, os 20 e poucos minutos que tive para apresentar meus argumentos aos juízes não foram suficientes, as perguntas vinham e me sentindo ameaçado eu buscava um subterfúgio nas respostas rápidas. Minha fala acompanhava o ritmo que meu coração ditava, e a verdade era que meus olhos sequer conseguiam notar a existência de outras pessoas que não os juízes e uma das voluntárias da competição, que era a responsável por apresentar o tempo restante da minha apresentação.

Essa foi uma das piores sensações da minha vida, de longe, sem contar que ainda hoje tento esquecer aqueles 20 minutos. Passei o restante da rodada ainda incrédulo com tudo que tinha acontecido, minha cabeça viajava a diversos locais e situações, maquinando tudo que eu tinha passado naquele breve momento de uma quinta-feira a tarde. Mas uma hora, tudo se acalmou. A rodada acabou, os juízes deram seu retorno, depois o nosso Coach e por fim as duas brilhantes estudantes que participavam da equipe. Depois que tudo passou, o suor frio, o nervosismo, a ansiedade, tudo, a única coisa que eu conseguia pensar era na próxima rodada, eu queria mais, mais daquela sensação, daquele momento único na vida de um estudante de direito, daquela sensação única que ainda hoje tenho problemas em explicar.

$\mathrm{Na}$ oportunidade, a competição acabou de forma precoce para a nossa equipe. Não tivemos êxito na fase classificatória, e acabamos não participando das finais daquele ano. Apesar disso, a sensação de dever cumprido, de superação, de orgulho eram sentimentos que permeavam nossa equipe, e nos fortaleceu para voltar no ano seguinte.

O ano de 2018 começou de forma diferente, a empolgação era ainda maior, enquanto o medo diminuia. Além disso, em minha vida profissional, que apenas se iniciava, tive minha primeira oportunidade em um escritório de advocacia. Foi então que tive que fazer a escolha mais difícil de toda a minha vida acadêmica, deixar a equipe da Jessup. Eu sabia que o trabalho e esforço necessário para participar da competição, por outro lado aquele era meu início em escritório, e por toda a breve experiência que tive naquele momento, não seria possível conciliar as duas atividades. De coração apertada, eu dei um "até logo" a Jessup e aos meus colegas de time.

Ainda nesse ano, tive a oportunidade de acompanhar a equipe de longe, podendo matar a saudade em uma breve oportunidade em que fui um dos juízes em um dos treinamentos para a preparação da rodada nacional da competição. Ainda assim, sentia um grande desconforto com o fim que aquela minha história com a competição iria tomando.

Foi no ano de 2019 que tomei, novamente uma decisão brusca, que alteraria positivamente minha história. Em um encontro com a equipe que estava se formando, demonstrei o meu claro desejo de voltar a competir, confidenciando que havia começado a me preparar para a seletiva da equipe, mas que havia desistido em função da quantidade de tarefas que tinha para aquele semestre. A época eu iria prestar o exame da ordem, estava pesquisando para a minha monografia, estudando uma outra língua, e estagiando 6 horas por dia. Apesar disso, a equipe me deu o total apoio, me acolhendo de volta de forma excepcional e única. Aquela era minha última oportunidade de competir, e eu jamais me perdoaria se não o fizesse.

Retornei a equipe, após a chancela do nosso professor orientador e da nossa treinadora. Foi o semestre mais intenso e gratificante de toda a minha graduação. Dessa vez, apesar da experiência pretérita, e de todo o arcabouço jurídico que tinha adquirido, o tempo me era escasso. E o que poderia se mostrar como um ótimo caso de superação pessoal em verdade foi um verdadeiro exemplo de trabalho em equipe e solidariedade que eu percebi em toda a nossa equipe.

A preparação foi árdua, os treinamentos e pesquisa foram intensos, e os momentos de estresse e frustração foram diversos. Até que enfim, chegou a tão esperada rodada nacional. Eram minhas últimas duas oportunidades de me postar perante os três juízes e apresentar meus argumentos, responder as brilhantes perguntas trazidas e vivenciar aquela experiência tão única que é o Jessup.

Foi então chegada a minha vez de apresentar meu discurso aos juízos. Após me prostrar perante o púlpito e respirar fundo, eu tive a melhor sensação da minha vida. Aquele não era somente o lugar que eu queria estar, mas sim o que eu devia estar. Minhas mãos ainda tremiam, meu coração claramente acelerou, mas daque- 
la vez eu aproveitei cada segundo do meu discurso, cada centésimo dos 21 minutos de minha apresentação, e foi inesquecível. A segunda rodada que me apresentei teve um gosto ainda diferente, eu sabia que poderia ser minha última oportunidade na Jessup, meus últimos minutos em frente a uma bancada de juízes em um moot court, apesar da angústias que os momentos finais de toda experiência ótima nos proporciona, saber que aquele poderia ser minha última oportunidade fez com que a experiência fosse muito mais prazerosa e bem aproveitada. Foi um momento único, que sedimentou aquela decisão de voltar a Jessup como a melhor de toda a minha vida.

Por fim, infelizmente não nos classificamos para as semifinais da competição, mas obtivemos ótimos resultados, sendo que fui escolhido como o melhor orador da competição, e fomos selecionados para representar o país nas rodadas internacionais da competição como um exbibition team.

O que restou de toda essa experiência foi o aprendizado com ótimos colegas de time, de coisas que vão além do acadêmico, do incremento claro na pesquisa ou lógica jurídica, além da melhora substancial na oratória e no inglês jurídico. Foi a importância de uma ótima equipe, de saber trabalhar em conjunto, de entender que os resultados podem ser pessoais mas são construídos em grupo, da motivação exarada pelos exemplos de superação que vivenciamos no dia-a-dia, dos retornos necessários e dos sacrifícios imprescindíveis a qualquer grande conquista.

\section{Os desafios de uma experiência desconhecida $^{8}$}

É certo que não é comum estudantes de direito no Brasil participarem de competições acadêmicas. Contudo, fazer parte da 'Jessup' transcende os ensinamentos da faculdade e, por isso, é sabido entre todos que participam que o impacto ultrapassa a experiência acadêmica.

Após integrar a comunidade da 'Jessup', um fator comum a todos os participantes é a capacidade de encarar suas maiores dificuldades e alguns de seus medos. Leva coragem enfrentá-los voluntariamente.

\footnotetext{
8 Ana Vitória Bokos. Membro da equipe nas edições 2019 e 2020.
}

Como membro do time, foi particularmente desafiador enfrentar as dificuldades da etapa oral da competição. O trabalho de meses se resume a cerca de 20 minutos apresentados em cada rodada. Para isso, a preparação individual foi árdua, mas dependeu também do trabalho em equipe e dos comentários construtivos para que pudesse atingir um bom desempenho.

Desenvolver a dicção, falar em bom tom, manter a calma, a respiração contínua e o contato visual são essenciais para uma boa oratória. Para pessoas introvertidas, no entanto, o que parece uma fórmula certa se torna um obstáculo. Quando as habilidades não são naturais, o preparo deve ser ainda maior e o cuidado consiste em não permitir que a pressão aumente e interfira nos resultados.

Além disso, a etapa oral exige uma boa capacidade persuasiva ao estruturar o discurso e responder questões. Para obter parte destas habilidades, é essencial ter uma pesquisa aprofundada.

Ao longo de duas edições da competição, pude entender sobre as principais problemáticas atuais do Direito Internacional Público, envolvendo a responsabilidade Estatal por ações corporativas em danos ambientais e violações de direitos humanos, apropriação de conhecimentos tradicionais de povos indígenas, sucessão automática de tratados, responsabilidade Estatal por sistemas de armas autônomas, conflito de jurisdição entre a Corte Internacional de Justiça e a Organização Mundial do Comércio e a detenção de Ministros perante o Tribunal Penal Internacional por crimes de guerra.

Como se vê, o aprendizado é diverso e extenso, sendo impossível uma única pessoa realizar toda a pesquisa no tempo disponibilizado. Não obstante, apesar de se tratarem de temáticas distintas, existe correlação entre os temas de cada edição, sendo necessário que cada membro consiga transitar entre as alegações de forma coerente e precisa. Para isso, as reuniões devem ser constantes ao longo do período de preparação, de modo a garantir uma boa comunicação entre os integrantes do time.

Fazer parte da 'Jessup' é no dia 28 de agosto já ter planejado um calendário de estudos e de reuniões até 16 de fevereiro do ano seguinte. É saber plantar para colher. É abrir mão dos momentos de diversão e descanso com o intuito de desenvolver-se. No início, é comum considerar que se trata de um caso de trade-off, uma troca daquilo que é certo e comum entre os estudantes 
universitários pela experiência desconhecida em uma competição internacional. Contudo, ao final a resposta é clara: vale a pena.

O esforço exigido, as horas dispendidas, a pesquisa incansável, o estresse e a ansiedade somados ao senso de pertencimento provocam o aprendizado que só pode ser obtido em competições como a 'Jessup'.

Neste ponto, importante ressaltar que se trata do pertencimento tanto à sua equipe, que acompanha cada passo da trajetória, como também à comunidade acadêmica envolvida com a competição - mais de 100 países, 700 Universidades, 3.000 estudantes pesquisando o mesmo caso pelo período de sete meses.

Ao chegar nas etapas orais e presenciais da competição, os participantes de equipes opostas acabam por debater sobre as possibilidades de resolução do caso, chegando a comentar sobre as particularidades dos próprios times, as realidades de suas universidades em relação ao apoio dado aos competidores, e até mesmo perspectivas pessoais sobre o direito. O mesmo acontece com os membros de apoio à competição e juízes convidados.

Assim, percebe-se o alcance a uma das missões da competição de incentivar a comunicação entre estudantes e juristas de diferentes partes do mundo, em um esforço para promover o entendimento e a cooperação internacional, bem como o avanço da educação jurídica ao motivar a compreensão mútua e a responsabilidade social enquanto estudantes e advogados. ${ }^{9}$

Neste sentido, é certo que participar da maior competição de Direito Internacional do mundo abre as portas às mais variadas oportunidades e integra o participante à uma comunidade profissional ativa e respeitada internacionalmente.

\section{0 acaso bem sucedido ${ }^{10}$}

Meu primeiro contato com a Jessup foi bem por acaso. Certo dia, abri um email sobre um processo seletivo para participar em um Tribunal simulado em inglês no ano de 2018. Não fazia ideia de como seria, mas me inscrevi pela curiosidade. Foi uma decisão que mudou

\footnotetext{
9 A missão da ILSA - International Law Students Association: https://www.ilsa.org/what-we-do/

10 Jefferson Seidy. Pesquisador da edição 2020.
}

minha vida.

A Jessup para mim foi uma grande escola de Direito Internacional que expandiu minha visão de uma maneira muito mais ampla e completa do que aprendemos na faculdade. Além disso, tive a oportunidade de ter um contato mais próximo do que acontece na prática sobre os conflitos entre Estados soberanos.

Outrossim, participar da Jessup como pesquisador me proporcionou uma experiência densa através dos estudos aprofundados e da análise e construção de argumentos de maneira a instigar um senso crítico na formulação de novas teses. Por conta disso, percebi os efeitos positivos na minha vida, por exemplo, trabalhos da faculdade, estágios e meu TCC, em que minha pesquisa passou a ser muito mais completa, rica e densa em material. Sem dúvidas, isso foi resultado do envolvimento com a Jessup, em razão das pesquisas que fiz e do suporte que prestei ao time, visto que tinha que esmiuçar cada ponto ao máximo, uma vez que atuei mais dando amparo em pesquisas e na busca de informações para a competição.

Além de ter participado como pesquisador, também tive a oportunidade de fazer parte do grupo de simulações que ocorriam semanalmente, e que são fundamentais para a preparação para a competição. Tal grupo me proporcionou tanto um desenvolvimento pessoal, como o aprimoramento da oratória em inglês, que não é muito comum esse tipo de experiência durante a graduação no Brasil. Essa experiência me fez desafiar e romper as barreiras que tinha, muitas vezes por conta da timidez, insegurança e achar não ser capaz.

Lembro na primeira simulação que participei e fiquei muito nervoso, com medo de esquecer os argumentos, mão gelada e a cabeça a todo vapor. No entanto, ao terminar a minha sustentação, senti uma sensação inesquecível de dever cumprido e de ter superado meus limites, ainda mais em inglês, expondo meus argumentos e trabalhando a oratória.

Com isso, hoje em dia, quando me pego um pouco inseguro em realizar alguma atividade ou apresentar algum projeto/trabalho, sempre lembro desses desafios que tive durante as simulações e meu pensamento muda, pois descobri que tenho competência para fazer qualquer coisa e que mesmo com medo, eu consigo encarar esses desafios.

Assim, no ano seguinte, tive a oportunidade de me juntar ao time como pesquisador e de estar na competi- 
ção em Florianópolis em 2020. Tal experiência foi muito interessante, além de ter sido inesquecível ver equipes de todo o Brasil que se esforçaram por vários meses mostrarem o seu trabalho durante as rodadas.

Tive a oportunidade de conhecer pessoas incríveis, de diversos estados, que provavelmente nunca teria o contato se não fosse pelo Jessup, que ainda mantenho contato e levarei para a vida.

A experiência que tive nos últimos anos me proporcionou um amadurecimento tanto na parte acadêmica como pessoal. Mesmo tendo contato com a Jessup como pesquisador, pude ter uma visão mais clara de como funciona a competição e como essa influencia de forma incomensurável a vida acadêmica de todos os estudantes que têm a oportunidade de participar.

\section{Um novo olhar acadêmico ${ }^{11}$}

Após alguns anos na graduação, compor um grupo de extensão nos últimos meses da vida acadêmica aparenta ser arriscado, tendo em vista a quantidade de demandas para um aluno de direito. Mas, fazer parte da Jessup começou como um desafio, mudando a minha perspectiva sobre o direito acadêmico na área do direito internacional.

Antes de adentrarmos na minha experiência, vale mencionar que a comunidade de direito internacional sempre aparentou ser bem restrita e, corriqueiramente, menosprezada por pesquisadores acadêmicos. Ao longo da minha formação, foram poucos encontros com o tema, e creio que esse seja o principal fator que acaba afastando alguns estudantes de direito.

Sendo assim, ao compor o time, pude perceber uma mudança na forma de pesquisar cientificamente, tendo em vista a rigorosidade acadêmica, metodológica e profissional, que diferencia a Jessup de outras atividades universitárias. Ouso dizer que a Jessup é uma academia para novos juristas, na qual temos a oportunidade de pesquisar sobre novos temas, e testar o poder da persuasão, em um curto espaço de tempo.

Neste sentido, o caso proposto pela ILSA (International Law Students Association), para um primeiro competidor, pode parecer bastante intimidador. A sua redação,

11 Gabriel Borba. Membro da equipe na edição 2020. e estruturação, é feita propositalmente para estimular o aluno a se especializar nos assuntos expostos, dedicando a pesquisar de forma que o desfecho resulte em bons argumentos. Consequentemente, o aluno deve utilizar o aprendizado a seu favor, manuseando as fontes de maneira coordenada com as pretensões das claims $^{12}$.

Por experiência própria, percebi que uma pesquisa bem fundamentada, que consiga englobar o tema de forma inteligente e objetiva, reflete principalmente na sua confiança na hora de argumentar sobre o caso. Por exemplo, trazer diversos argumentos diferentes demonstra o seu entendimento sobre a problemática, possibilitando uma segurança jurídica maior na hora da argumentação. Assim, se fosse possível dividir a importância da pesquisa em porcentagem, diria que as fontes de pesquisa são $60 \%$ e, a forma que elas são utilizadas, e estruturadas, comportam os outros $40 \%$.

Geralmente, testar o seu poder de argumentação, e persuasão, no curso de direito é raro, havendo poucas oportunidades para aperfeiçoamento. Entretanto, com a Jessup, é possível testar e aprimorar as suas habilidades, potencializando-as, vez que estamos lidando com outra língua.

Portanto, ao treinar para as rodadas nacionais, o estudante tem a chance de melhorar a sua argumentação e se acostumar com interrupções e questionamentos. Por experiência própria, enfatizo que essa é uma das partes mais trabalhosas, pois requer um pensando ágil e ousado, treinando você para responder qualquer tipo de indagação, da melhor forma possível.

Ter a oportunidade de lapidar a sua argumentação é primordial para alguém que irá trabalhar na área jurídica. Além disso, a Jessup promove uma forma de enxergar o direito internacional como algo interseccional, em outras palavras, dá a oportunidade de vislumbrar que o direito internacional reverbera em todos os campos jurídicos, o que é ótimo para aqueles que gostam do tema e querem utilizá-lo em seus trabalhos acadêmicos e profissionais.

Nesse contexto, os primeiros resultados deste compromisso puderam ser visualizados logo após o final das rodadas nacionais, reverberando diretamente no meu projeto de conclusão de curso e, consequentemente, na

12 O caso é dividido em quatro claims para cada lado (applicant e respondent), logo, a pesquisa do aluno, tem por objetivo achar argumentos suficientes para defender o litígio em questão. 
minha defesa. A Jessup trouxe um novo olhar acadêmico, acarretando em novas formas de pesquisa e argumentação, impulsionando ainda mais o meu artigo científico.

Assim, principalmente na época da monografia, onde existe uma angústia entre os estudantes de direito, até mesmo pelo fato de não haver uma cultura de aperfeiçoar a oratória e metodologias de pesquisa ao longo do curso, pude perceber uma confiança maior no meu trabalho e naquilo que eu estava defendendo.

Ademais, a experiência da Jessup só é possível através de um grupo de estudantes que se empenham para obter um resultado em comum. Tudo depende da sincronia daqueles que compõem o time, tendo em vista que o trabalho em equipe é fundamental. A orientação do professor responsável pela equipe, junto com as experiências de outros colegas como Nayara, Ana, Jefferson, Gilda e Igor possibilitam que você consiga ter a melhor vivência possível, sempre lhe incentivando para o crescimento do seu conhecimento dentro do projeto. Ouvir críticas de seus pares e conversar sobre estratégias, pesquisas e argumentação é fundamental para evoluir gradativamente, acarretando em bons resultados.

Deste modo, apesar de toda a experiência do Jessup parece ser bastante intimidadora, ao longo da experiência você percebe a importância da rigorosidade, e do comprometimento com a simulação. Tal experiência abre portas para pesquisas sobre novos temas e lhe tira da zona de conforto com inúmeros desafios. Mas, todo o esforço plantado, ao longo dos meses, é recompensado nas mais diversas formas, a curto, médio e longo prazo, seja dentro da academia ou na vida profissional.

\section{0 resultado da experiência prática}

Sendo uma competição a nível universitário, por óbvio, a participação na Jessup traz ganhos acadêmicos e profissionais inestimáveis. Afinal, por este motivo a competição foi criada: oportunizar que estudantes experienciem, na forma de simulação, uma controvérsia perante a Corte Internacional de Justiça. O inesperado é considerar a infinidade de ganhos pessoais.

Assim, criar planejamentos a curto e médio prazo, desenvolver estratégias, trabalhar em conjunto, dependendo diretamente do trabalho dos outros membros da equipe, aprender a manter a calma em ambiente de estresse e pressão, entre outros, são vantagens e aprendizados que não estão limitados à profissão.

Ademais, a possibilidade de se conectar a pessoas de diferentes realidades e ter contato com suas perspectivas quanto às problemáticas internacionais, permite a troca de costumes, tradições, oportunidades e conhecimentos acerca de sistemas jurídicos, em um espírito de diálogo crítico e cooperação internacional.

Os benefícios que a nossa experiência com a Jessup nos trouxe são inestimáveis e continuam se provando com o tempo e com nosso amadurecimento no Direito, seja iniciando os semestres finais do curso, seja ingressando no mercado de trabalho e em programas de pós-graduação lato sensu.

As habilidades desenvolvidas com a competição são extremamente úteis em todos esses aspectos, sendo, inclusive, consideradas como diferencial curricular, principalmente quando o candidato vem de países e jurisdições onde a prática de tribunais simulados não faz parte do currículo tradicional das faculdades de Direito ${ }^{13}$.

Assim, a verdade é que a nossa experiência com a Jessup é coletiva, vivemos, crescemos, aprendemos e nos desenvolvemos com ela e em conjunto, mas foi preciso individualizá-la para entender o real impacto que uma competição de tribunal simulado em direito internacional pode proporcionar.

Mais do que uma experiência acadêmica, a Jessup é um divisor de águas na vida de todos aqueles que têm a maravilhosa oportunidade de participar da competição.

13 WHITE \& CASE. Jessup Guide: using Jessup skills in your legal career. Disponível em: file:///C:/Users/06250420347/ Downloads/156655-Texto\%20do\%20artigo-342866-1-10-20190408. pdf . Acesso em: 13 jul 2020 
Para publicar na Revista de Direito Internacional, acesse o endereço eletrônico www.rdi.uniceub.br ou www.brazilianjournal.org.

Observe as normas de publicação, para facilitar e agilizar o trabalho de edição. 